\title{
Interactive Editing of Circuits in a Step-Based Tutoring System
}

\section{Dr. Brian J Skromme, Arizona State University}

Dr. Brian J. Skromme is a Professor in the School of Electrical, Computer, and Energy Engineering and was Assistant Dean of the Fulton Schools of Engineering at Arizona State University from 2011-19. He holds a Ph.D. in Electrical Engineering from the University of Illinois at Urbana-Champaign and was a member of technical staff at Bellcore from 1985 to 1989. His research interests are in engineering education, development of educational software, and compound semiconductor materials and devices.

Caleb Redshaw, Arizona State University

Caleb Redshaw is an undergraduate student of Mechanical Engineering at Arizona State University.

Mr. Abhishek Gupta

Mr. Shatrughn Gupta, Arizona State University

Prof. Petru Andrei, Florida A\&M University/Florida State University

Dr. Petru Andrei is Professor in the Department of Electrical and Computer Engineering at the Florida A\&M University and Florida Stat University (FAMU-FSU) College of Engineering. He is the FSU campus education director for the NSF-ERC Future Renewable Electric Energy Delivery and Management Systems Center (FREEDM) and has much experience in recruiting and advising graduate, undergraduate, REU, and K-12 students, as well as in working with RET teachers. Dr. Andrei has published over 100 articles in computational electronics, electromagnetics, energy storage devices, and large scale optimization methods.

Dr. Hector Erives, University of Texas at EI Paso

Dr. DeAnna Bailey, Morgan State University

DeAnna Bailey received her B.S (2003) in electrical engineering and D.Eng (2013) from Morgan State University, Baltimore, MD. In 2017, she joined the Electrical and Computer Engineering Department at Morgan State University where she teaches circuit and signal processing classes. Her interest is developing innovative technology that uses artificial intelligence to facilitate and enhance the learning of engineering concepts and principles.

\section{Dr. Willie L Thompson II, Morgan State University}

Dr. Willie L Thompson, II is an Associate Professor of the Electrical and Computer Engineering Department within the Clarence M. Mitchell, Jr. School of Engineering (SOE). Dr. Thompson serves as the Director for the Laboratory for Tactical and Communication Systems, which focuses on research for the design, implementation, and security of advanced wireless embedded systems. Dr. Thompson secured and led the SOE's first DoD prime contract for the development of a multi-band, multi-mode software-defined radio (SDR) for next-generation DoD telemetry applications. In addition, he led the development of a NASA SDR Testbed for space communication technologies. During his industry tenure, Dr. Thompson served as PI for NASA Goddard Space Flight Center (GSFC) SDR Technology Program from 2005 to 2009 and designed an RF front end for a GPS receiver for Hubble Servicing Mission 2 in 2008. Dr. Thompson has over 15-years of experience in the areas of RF/microwave engineering and communication systems. His technical expertise includes RF/microwave component and circuit design, multi-band transceiver design, software-defined radio, embedded software/firmware, and system-on-chip (SoC) development.

\section{Dr. Srividya Kona Bansal, Arizona State University}

Srividya Bansal joined Arizona State University in Fall 2010 as Assistant Professor. Prior to joining ASU she was a Visiting Assistant Professor at Georgetown University in Washington, D.C. She also worked in the industry for 5 years as a Software Engineer at SAP Labs India and Tyler Technologies 
in Plano, TX. Her primary research focuses on semantics-based approaches for Big Data Integration, Web service description, discovery \& composition, and tools for outcome-based instruction design in STEM education. She is also interested in Software Engineering Education research that focuses on experimenting various delivery models in project-centric courses. She designed and developed a Web service description language called USDL (Universal Service-Semantics Description Language). She is the principal investigator of the Instructional Module Development System (IMODS) that is currently under development and funded by National Science Foundation.

\section{Wendy M. Barnard, Arizona State University}

Wendy Barnard is an Assistant Research Professor and Director of the College Research and Evaluation Services Team (CREST) at Arizona State University. Dr. Barnard received her Ph.D. from the University of Wisconsin-Madison, where she focused on the impact of early education experiences and parent involvement on long-term academic achievement. Her research interests include evaluation methodology, longitudinal research design, STEM educational efforts, and the impact of professional development on teacher performance. Currently, she works on evaluation efforts for grants funded by National Science Foundation, US Department of Education, local foundation, and state grants. 


\title{
Interactive Editing of Circuits in a Step-Based Tutoring System
}

\begin{abstract}
Step-based tutoring systems are known to be more effective than traditional answer-based systems. They however require that each step in a student's work be accepted and evaluated automatically to provide effective feedback. In the domain of linear circuit analysis, it is frequently necessary to allow students to draw or edit circuits on their screen to simplify or otherwise transform them. Here, the interface developed to accept such input and provide immediate feedback in the Circuit Tutor system is described, along with systematic assessment data. Advanced simplification methods such as removing circuit sections that are removably hinged, voltage-splittable, or current-splittable are taught to students in an interactive tutorial and then supported in the circuit editor itself. To address the learning curve associated with such an interface, $\sim 70$ video tutorials were created to demonstrate exactly how to work the randomly generated problems at each level of each of the tutorials in the system. A complete written record or "transcript" of student's work in the system is being made available, showing both incorrect and correct steps. Introductory interactive (multiple-choice) tutorials are now included on most topics. Assessment of exercises using the interactive editor was carried out by professional evaluators for several institutions, including three that heavily serve underrepresented minorities. Both quantitative and qualitative methods were used, including focus groups, surveys, and interviews. Controlled, randomized, blind evaluations were carried out in three different course sections in Spring and Fall 2019 to evaluate three tutorials using the interactive editor, comparing use of Circuit Tutor to both a commercial answer-based system and to conventional textbook-based paper homework. In Fall 2019, students rated the software a mean of 4.14/5 for being helpful to learn the material vs. 3.05/5 for paper homework (HW), $p<$ 0.001 and effect size $d=1.11 \sigma$. On relevant exam questions that semester, students scored significantly ( $p=0.014$ ) higher with an effect size of $d=0.64 \sigma$ when using Circuit Tutor compared to paper HW in one class section, with no significant difference in the other section.
\end{abstract}

\section{Introduction}

A meta-analysis has shown that step-based tutoring, where each step of a student's work is immediately evaluated, is considerably more effective than answer-based tutoring (where only the final answer to a problem is checked) and is almost as effective as a skilled human tutor. Specifically, step-based systems caused improvements of $0.76 \sigma$, compared to $0.31 \sigma$ and $0.79 \sigma$ for answer-based systems and human tutors, respectively ( $\sigma$ denotes standard deviation) [1]. Previously, we have described a step-based tutoring system in the domain of linear circuit analysis, which is a crucial gateway course in the education of both electrical and many nonelectrical engineers [2-10]. This system features automatic problem generation, where an unlimited number of unique circuit diagrams (not just element values) are created for every user. It provides an unlimited supply of fully worked and explained examples that are isomorphic to the actual problems and has pedagogical features such as automatic coloring of nodes. It further includes specialized interfaces to accept equations, simplified equations, matrices, and numerical answers using a template-based interface to scaffold learning, and an interactive on-screen circuit editor. Students are graded solely on completion of the required number of problems without excessive errors and are allowed to "give up" on any problem and view a fully explained solution 
without any grade penalty. Instead, they are just given a new problem of the same type to complete, to support mastery learning. Introductory interactive tutorials provide instruction on the required concepts and methods prior to starting the examples and exercises in a game-like format. (The gamification elements currently incorporated in our system include completion certificates, clearly defined progressive levels of difficulty, immediate feedback including sound effects to reinforce progress, and scaffolded learning with increasing challenges. Further items such as a point system and leaderboards are planned in future work. Gamification has frequently been found to improve learning and engagement [11].)

Prior controlled, randomized experiments have shown a $1.21 \sigma$ improvement in learning on writing nodal analysis equations and identifying elements in series and parallel in a laboratorybased experiment and a corresponding improvement of $0.91 \sigma$ in student motivation [3, 4]. A classroom-based assessment in Fall 2014 using random assignment to compare this system to complete nodal and mesh analysis exercises to using the commercial WileyPLUS system found a $0.41 \sigma$ improvement in that homework score $(p<0.008)$ [7]. It was also observed that $32-34 \%$ of WileyPLUS users voluntarily completed additional problems in the step-based system for no credit, whereas no users of the step-based system did the reverse [7]. (Surveys and post-tests were not used in this case.) This comparison was repeated in Fall 2015 with addition of a survey and post-test, finding a $0.72 \sigma$ improvement in average post-test scores on nodal analysis when using Circuit Tutor from $49 \%$ to $72 \%(p<0.05)$ and no significant difference on mesh analysis (corresponding post-test scores of $65 \%$ and $71 \%)(p=0.38)[8,9]$. The survey showed $86 \%$ of students preferred the step-based system and only 9\% preferred the commercial answer-based system, and 94\% felt the step-based system taught them more effectively and only 3\% felt that way about the publisher system [8, 9]. Another classroom-based experiment at a large private university in Fall 2014 found a $0.97 \sigma$ improvement $(p<0.001)$ in post-test scores (using pre-test scores as a covariate) using the step-based system in comparison to using paper exercises to teach concepts of series-parallel relationships [9]. However, reliable results could not be obtained for nodal or mesh analysis in that case due to the lack of random assignment and large differences in pre-test scores.

Here, we describe extensions to the step-based system including the ability to shift or "split" a circuit to create room to insert new elements in the circuit editor, to provide immediate feedback on the correctness of various circuit editing operations, support for advanced simplification methods, video help to ease the learning curve for the user interface, new introductory interactive tutorials on most of the topics, and automated generation of transcripts of student work to aid later review and studying.

Further, we describe extensive assessment of the system by an independent evaluation team including both qualitative and quantitative methods. We describe experiments conducted in Spring 2019 to compare use of this system to use of a commercial, publisher-based system (WileyPLUS) and in Fall 2019 to compare it to use of traditional paper-based homework (HW) from a textbook. The focus on these experiments is on analysis methods requiring use of the circuit editor, including superposition, source transformation, and finding Thévenin and Norton equivalent circuits. Students were randomly assigned to use either the step-based system, or WileyPLUS or paper homework, and then surveyed to learn their opinions of the different approaches as well as tested using quizzes and exams to compare their learning of the relevant material. Blind evaluations were used. Student preferences strongly favored the step-based 
system over both alternative approaches and learning outcomes showed statistically significant improvements in some class sections but not in others. Surveys were conducted in several different institutions, including several that heavily serve underrepresented minority students, to assess the suitability of the system for diverse groups of learners.

\section{Enhanced Interactive Circuit Editor}

The basic features of the step-based system have been described previously, including the threestep problem generation algorithm that creates and validates its own randomly-generated circuit problems, the automated solution and explanation generation algorithms, and the interfaces used to accept and evaluate equations, simplified equations, matrix equations, waveform sketches, and numerical answers [2-10]. A preliminary version of the on-screen circuit editor has also been described $[5,6]$. Here, we describe enhancements of the latter to support problems involving superposition, source transformation, and finding Thévenin and Norton equivalent circuits.

The circuit editor (in unrestricted mode) allows students to change element values and polarities, to transform any element into a different type (including short and open circuits), to modify sought currents, voltages, or powers (i.e., unknowns) or control variables for dependent sources on any element, to drag any element to a new position on the editing grid, and to add a new element anywhere on the grid (see Fig. 1 for an example). As there may be insufficient "room" on the editing grid to carry out operations such as source transformations, it also now permits students to shift, split, or compress a circuit as needed to accomplish those tasks. On exiting the editor, the circuit is extensively validated to make sure it is soluble and does not have problems such as disconnected, dangling, or shorted elements and is not more generally "hinged" as discussed elsewhere [12]; i.e., has two or more portions connected only by single wires that are therefore effectively isolated. The editor also now supports terminals such as those needed for Thévenin or Norton equivalent circuits or for "viewing” input impedances, etc., as shown in Fig. 1. Both AC and DC circuits are supported.
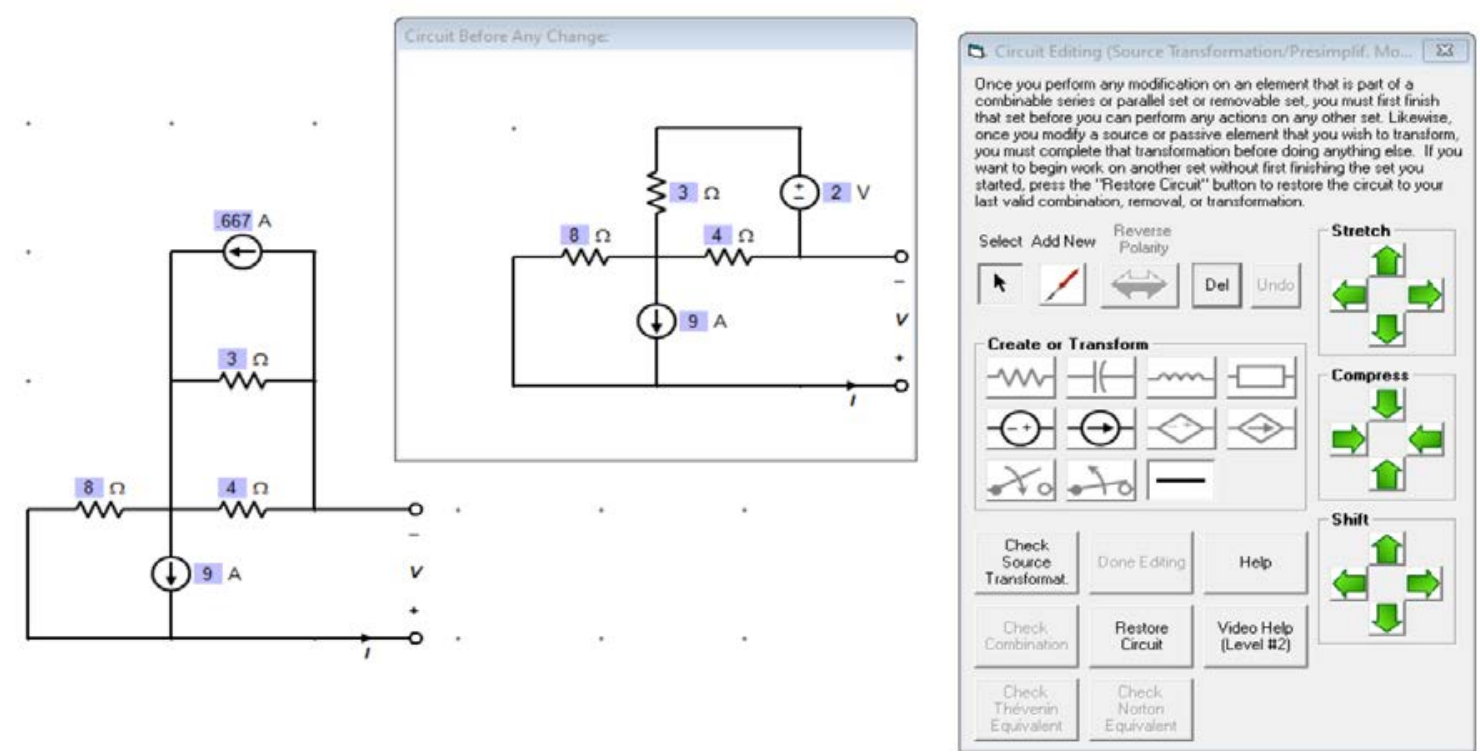

Fig. 1. Example of the circuit editing interface being used to carry out a source transformation in a Thevenin/Norton equivalent circuit problem. 
The unrestricted editing mode does not however check if students have made specific desired changes in a circuit, however. Its use is currently limited to drawing the final Thévenin or Norton equivalent circuits in problems of that type. Instead, we have implemented four "restricted" editing modes in which student work is checked for validity. In the first, "sourcekilling" mode, the only permitted operation is to "turn off" either independent current or voltage sources in superposition problems by changing them to open or short circuits, respectively. Attempts to do other operations are stopped with warning messages. Mistakes when killing sources are tallied and making excessive mistakes forfeits credit for a problem (though the problem can still be completed for no credit if the student is invested in it). Students can exit this mode after killing sources correctly to finish the analysis of a given child circuit with only one independent source.

In the second, pre-simplification mode, students can combine passive elements in series and parallel, can combine independent sources in series and parallel, and can delete any shorted or "dangling” elements that do not have sought quantities. They can also change "redundant" elements (e.g., those in series with current sources or in parallel with voltage sources, which therefore have no effect on the rest of the circuit) into short or open circuits, as appropriate. They can also carry out advanced simplification methods as discussed in Ref. [12], including removing sections of a circuit that are removably "hinged," "voltage-splittable” or "currentsplittable" (i.e., are isolated from the rest of the circuit by "chains" of voltage or current sources that cause them to have no effect on the rest of the circuit), as long as the removed section and isolating sources have no sought variables. Those methods are taught to students in the introductory tutorial, as circuits textbooks typically do not discuss them. Situations where they are relevant frequently occur in superposition and transient (switched) circuit problems. After each individual operation, the student must check the validity of that operation by clicking a button before proceeding to other operations, to facilitate the checking procedures. Errors are always counted, and excessive errors forfeit problems as noted above.

In the third restricted mode, presimplification using the above methods is possible but "soughtvariable transformations" are also permitted [10]. This procedure (introduced in the introductory tutorial) is relevant, for example, when one wishes to combine elements in series when one of them has a sought voltage or power, which would be destroyed by the simplification. Another case is combining elements in parallel when one of them has a sought current or power, which would again be destroyed. In these cases, students are allowed to replace the sought variable that impedes simplification by one that does not, and in doing so is prompted to write an "auxiliary equation” that relates the old sought variable to the newly created one, so that the deleted variable can still be calculated. For example, a sought voltage on a series element can be replaced by a sought current on that same element (or on another element in series with it), relating the two via Ohm's law. This approach avoids having to go back to a previous circuit diagram to calculate the originally desired variable and makes the process straightforward. As always, errors are tallied and limited. This mode is available both before and after killing sources in superposition problems, for example.

In the fourth restricted mode, illustrated in Fig. 1, presimplification with sought variable transformations are similarly allowed, in addition to source transformations between voltage sources in series with a passive element and current sources in parallel with the same element (provided that those elements lack sought quantities). Source transformations are not however 
permitted when other simplifications are available, as the latter should generally be completed first. Shifting, splitting, and compression operations are available in this mode to help "make room" on the grid for the operations when necessary. Further, the last valid circuit is always shown in an inset window, which is particularly useful when constructing source transformations. This mode is used in both source transformation and Thévenin/Norton equivalent circuit problems. As always, each individual transformation or simplification must be checked before performing a different operation, which helps in providing feedback on specific errors a student may make. Use of these restricted editing modes greatly facilitates checking student work, which would otherwise be extremely challenging. Appropriate text-based and video help are available at all times to help students learn the interfaces. An illustration of the support for advanced simplification methods is shown in Fig. 2.

\section{New Student Support Features}

Prior to 2019, introductory expository multiple-choice tutorials in an interactive format were available for only 5 of the 18 games available at that time. A total of 21 available games are now available with introductory tutorial support for 20 of them (the remaining game is not yet fully released, and a tutorial will be added when it is). These tutorials explain all of the basic concepts required to work problems and may well even be able to replace a conventional textbook once the scope of our system is expanded to cover all relevant topics. Unlike conventional textbooks, this interactive system enables monitoring of student activity and completion including time on task and the correctness or incorrectness of their answers to multiple choice questions.

Interactive textbooks of this type are known to be effective in engaging students to read them and improve their success [13-15].

Another new feature introduced starting in Spring 2019 and much more heavily in Fall 2019 and Spring 2020 is video help for each level of each game in the system (a total of 71 videos to date, each typically between 5 and 35 minutes in length). These videos are publicly available in YouTube [16] and illustrate both the operation of the user interfaces as well as the technical aspects of working the problems. Direct links to the appropriate video are available within the software at all appropriate places. They include one that is a general introduction to the system 
and special videos illustrating such topics as doing complex number calculations on calculators (which is often difficult for students) and Gaussian elimination. Where complex number calculations are required to work problems, a calculator emulator is used in the videos to illustrate the procedures, and handwritten algebra is shown on problems requiring algebraic calculations (including AC problems involving complex coefficients, a particular source of difficulty). These videos have proven quite popular with and helpful to students; some have been watched 500 or more times to date.

Another feature being released in Spring 2020 is automatically generated "transcripts" of student work on each problem in a PDF format, showing both correct and incorrect steps they took (labeled as such). A section of a sample transcript is illustrated in Fig. 3. These transcripts are intended to address a key limitation of step-based tutoring systems, namely that students do not normally have any record of the series of steps they took on the screen to solve a problem as they would when working a similar problem on paper. They are expected to be useful to students for later studying and reviewing for exams. The first one created is displayed automatically to students, and subsequent transcripts are accessible directly within the user interface.

\section{Randomized Comparisons of the Step-Based Tutoring System to a Publisher-Based System or Paper Homework}

\subsection{Spring 2019 Comparison to WileyPLUS}

We carried out a randomized, blind comparison of this system to a commercial answer-based system (WileyPLUS) in Spring 2019 as described in more detail elsewhere [10]. Students in one section of the first author's course at Arizona State University (ASU) $(N=64)$ were randomly assigned to groups A and B. Group A was required to use Circuit Tutor for the topic of DC superposition, and to do similar problems in WileyPLUS (for the Irwin \& Nelms textbook [17]) for the topic of DC source transformations as part of one homework assignment. Group B did the reverse, so that both groups used both systems for part of this homework. Videos of problems being worked were available in both Circuit Tutor and in WileyPLUS, but Circuit Tutor did not have introductory tutorials available on these topics at the time of this experiment. Students relied on lectures and the textbook for an introduction to the topics. A single 12-point problem on each topic within a 100-pt. midterm exam was used as a post-test (on the day after the homework was due), and no pre-test was administered given that random assignment should 
TABLE 1. POST-TEST RESULTS FROM RANDOMIZED EXPERIMENT IN SPRING 2019.

\begin{tabular}{lcccc}
\hline & \multicolumn{2}{c}{ Superposition } & \multicolumn{2}{c}{ Source Transformation } \\
& Circuit Tutor & WileyPLUS & Circuit Tutor & WileyPLUS \\
\hline \hline$N$ & 32 & 32 & 32 & 32 \\
Post-Test Item Score $(0-12)$ & $6.59(4.49)$ & $6.29(2.80)$ & $6.71(4.58)$ & $5.91(2.41)$ \\
\hline
\end{tabular}

Values in parentheses are standard deviations.

avoid significant differences between groups. A survey was subsequently administered to both groups to assess student opinions of both systems and had a $67 \%$ response rate. The average scores on the post-test (midterm exam) questions are shown in Table I and were slightly higher in both cases for Circuit Tutor users, but the differences were not statistically significant using a student's $t$-test $(p=0.92$ and $p=0.56)$. Results of the student preference survey are shown in Fig. 4 and indicate strong preferences for Circuit Tutor over WileyPLUS for both topics. Qualitative analysis of student comments showed that students preferred the step-based guidance offered by Circuit Tutor, the interactivity and explanations given at the end of each problem, and the immediate feedback [10]. A few students however preferred working problems on paper and a few preferred the greater number errors allowed in WileyPLUS.

\subsection{Fall 2019 Comparison to Paper Homework}

Another randomized experiment was conducted in two sections of the same ASU course in Fall 2019 to compare Circuit Tutor to conventional paper homework using problems from a textbook [17]. In this case, three different tutorials on DC superposition, DC source transformations, and DC Thévenin/Norton equivalent circuits were tested, along with a tutorial covering similar problems in AC phasor analysis. Optional introductory tutorials were included on all of the DC topics in this instance. Students in both sections were randomly assigned to groups A and B, where group A completed a homework assignment on the three DC topics in Circuit Tutor and the corresponding AC topics using paper homework later in the semester, and group B did the reverse. No pre-test was used in view of the use of random assignment, but students took a quiz on the due date of the HW consisting of one problem on superposition and one on

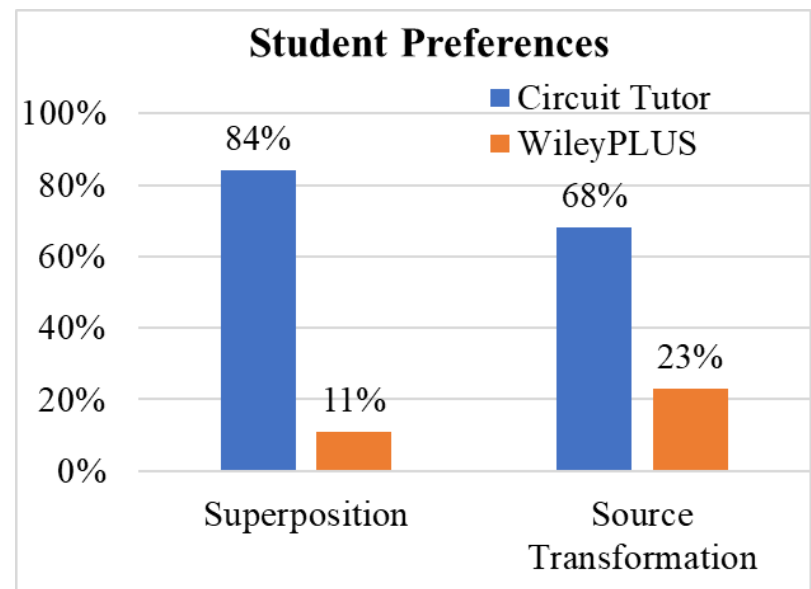

Fig. 4. Results of a survey comparing student preferences between Circuit Tutor and WileyPLUS in Spring 2019.
Thévenin/Norton equivalent circuits (the latter being easiest to complete using source transformations). Those problems were derived from a different textbook to avoid bias towards either system. They further had two problems on a midterm exam given two days later on the same two topics worth 18 and 20 pts., respectively, on the 100-pt. exam (somewhat different quizzes and exams were given in the two sections). The superposition problem was again taken from another textbook, but the Thévenin/Norton problem was generated using Circuit Tutor. Students who had been assigned to use paper HW however strongly requested access to Circuit Tutor after the quiz but prior to the midterm 
TABLE 2. RESULTS FROM RANDOMIZED EXPERIMENTS IN FALL 2019.

\begin{tabular}{|c|c|c|c|c|}
\hline & \multicolumn{2}{|c|}{ DC Analysis } & \multicolumn{2}{|c|}{ AC Analysis } \\
\hline & Circuit Tutor & Paper HW & Circuit Tutor & Paper HW \\
\hline $\begin{array}{l}\text { Total Quiz Scores (0-100), } \\
\text { Section } 1\end{array}$ & $\begin{array}{c}53.4 \\
(33.3,29)\end{array}$ & $\begin{array}{c}57.7 \\
(32.4,31)\end{array}$ & N/A & N/A \\
\hline $\begin{array}{l}\text { Total Quiz Scores (0-100), } \\
\text { Section } 2\end{array}$ & $\begin{array}{c}53.0 * \\
(27.6,30)\end{array}$ & $\begin{array}{c}38.3 * \\
(24.4,32)\end{array}$ & N/A & N/A \\
\hline $\begin{array}{l}\text { Combined** Exam Item } \\
\text { Scores (\%), Section } 1\end{array}$ & $\begin{array}{c}63.6 \\
(32.1,29)\end{array}$ & $\begin{array}{c}62.6 \\
(27.0,31)\end{array}$ & $\begin{array}{c}77.7 \\
(28.7,29)\end{array}$ & $\begin{array}{c}69.4 \\
(33.1,31)\end{array}$ \\
\hline $\begin{array}{l}\text { Combined** Exam Item } \\
\text { Scores (\%), Section } 2\end{array}$ & $\begin{array}{c}65.4^{*} \\
(27.3,30)\end{array}$ & $\begin{array}{c}46.9 * \\
(27.6,32)\end{array}$ & $\begin{array}{c}70.7 \\
(28.2,30)\end{array}$ & $\begin{array}{c}66.7 \\
(31.8,32)\end{array}$ \\
\hline $\begin{array}{l}\text { Relevant HW Score (\%), } \\
\text { Section } 1\end{array}$ & $\begin{array}{c}65.0 \\
(41.7,29)\end{array}$ & $\begin{array}{c}71.2 \\
(37.2,31)\end{array}$ & $\begin{array}{c}75.6 \\
(31.0,29)\end{array}$ & $\begin{array}{c}74.6 \\
(23.2,31)\end{array}$ \\
\hline $\begin{array}{l}\text { Relevant HW Score (\%), } \\
\text { Section } 2\end{array}$ & $\begin{array}{c}87.7 * \\
(23.9,30) \\
\end{array}$ & $\begin{array}{c}69.6^{*} \\
(40.2,32) \\
\end{array}$ & $\begin{array}{c}65.5 \\
(31.1,30) \\
\end{array}$ & $\begin{array}{c}62.1 \\
(37.9,32) \\
\end{array}$ \\
\hline $\begin{array}{l}\text { Main values are means. Val } \\
* \text { Statistically significant diff } \\
\text { **Combination of two quest } \\
\text { question score worth } 22 \text { poin }\end{array}$ & $\begin{array}{l}\text { parentheses } \\
\text { with } p \leq 0 \text {. } \\
\text { res totaling } \\
\text { of } 100 \text { for } A\end{array}$ & andard d & $\mathrm{ns}, N)$. & 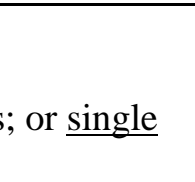 \\
\hline
\end{tabular}

exam. Such access was therefore granted in both sections, resulting in cross-contamination of the groups prior to the exam. All students could access paper HW problems in their textbooks at any time if they so desired, though it seems unlikely based on survey preference data that many did so. A post-test was given after the later HW assignment on AC phasor analysis using those methods in the form of one 22 pt. problem on AC Thévenin/Norton equivalent circuits (the latter being easiest to complete using source transformations) on the second midterm exam, which was worth 100 pts. total. Students at this stage had used both Circuit Tutor and paper HW on the topics in question for either AC or DC circuits, however, so this was not a very clear comparison of the two approaches. Surveys were assigned after both the DC and AC HW assignments on these topics to compare student preferences, worth 20 pts. of extra credit each on the 150 pt. HW assignments. Response rates on the two surveys were $57 \%$ and $87 \%$, respectively, in the first section; and 69\% and 82\%, respectively, in the second section.

The results of the assignment scores, post-test (quiz) scores, and post-test (exam problem) scores are shown in Table 2. (No quiz was given on the AC Analysis topics.) Statistically significant improvements for the students using Circuit Tutor were found for the DC Analysis quiz scores in Section $2(p=0.046$ with a an effect size of Cohen $d=0.54 \sigma)$, the DC Analysis combined exam question scores in Section $2(p=0.014, d=0.64 \sigma)$, and for the DC Analysis homework scores in Section $2(p=0.050, d=0.34 \sigma)$. The individual exam question scores also showed significant differences in that section (not shown). No significant differences were found for any item in Section 1, however, or for the AC Analysis items in either section. It is therefore of interest to examine why significant differences were found for one class section but not the other. The same instructor taught both sections (though Section 1 had an undergraduate teaching assistant and Section 2 did not) and lectures were very similar. Homework assignments were identical, and the midterm exams were very similar. One difference seems to be that Section 2 students 
completed the Circuit Tutor exercises at a higher rate than did the Section 1 students, as those HW grades are based on successful completion only. The students assigned to do paper HW had comparable HW scores in both sections. It would seem natural that students doing more work in Circuit Tutor could benefit more from it, as is observed, but it is also not clear why they did so in one section more than in the other. Overall, the instructor observed that Section 1 was on average academically stronger than Section 2, as the scores on similar first and second midterm exams were 65.5 and 71.5, respectively, in Section 1; and 57.2 and 63.9, respectively, in Section 2. It may therefore be that academically weaker students benefit more from step-based instruction, whereas stronger students do relatively well with either type of instruction.

The cross-contamination of the two groups noted above on the DC Analysis exam question scores should not be a major factor, though it may reduce the effect sizes we found. That effect would likely improve the performance of those assigned to do paper HW, who were more likely to cross over and use Circuit Tutor. In Section 1, five students completed anywhere from 3-9 of the 9 problems in Circuit Tutor, and in Section 2, two students completed from 3-5 of the 9 Circuit Tutor problems after the quiz and before the exam on DC Analysis. As this effect should if anything enhance the scores of the students doing paper HW, it cannot account for the larger difference between the two groups in Section 2. The number of students assigned to do Circuit Tutor who also did paper HW problems is unknown, but based on the survey results discussed below, is likely to be very small in both sections. It is probably not surprising that no significant differences were found on the AC Analysis problem, given that both groups had by that time used both Circuit Tutor and paper homework on the analysis techniques in either the AC or DC domains (effectively very high cross-contamination). The assignment of groups on the AC topics was done mainly to balance the amount of Circuit Tutor and paper HW for all students in the interest of fairness.

Results from the survey given on the DC Analysis homework assignment in Fall 2019 are shown in Table 3. Large, statistically significant differences were found in the comparison of Circuit Tutor to paper HW, in that students found that the former helped them learn better, was easier to

TABLE 3. SURVEY RESUltS FOR A HW ASSIGNMENT ON DC ANALYSIS METHODS IN FALL 2019.

\begin{tabular}{|c|c|c|c|c|c|}
\hline Survey Question & $\begin{array}{c}\text { Circuit } \\
\text { Tutor } \\
(N=43) \\
\end{array}$ & $\begin{array}{c}\text { Textbook } \\
\text { Problems } \\
(N=41) \\
\end{array}$ & $p$-value & $t$ & $\begin{array}{c}\text { Cohen's } \\
d\end{array}$ \\
\hline $\begin{array}{l}\text { To what extent did this HW assignment } \\
\text { help you learn the course material? ( } 1=\text { none } \\
\text { at all; } 5=\text { a great deal) }\end{array}$ & $\begin{array}{l}4.14 \\
(.92)\end{array}$ & $\begin{array}{c}3.05 \\
(1.12)\end{array}$ & 0.000 & 4.883 & 1.11 \\
\hline $\begin{array}{l}\text { How easy or difficult it was for you to } \\
\text { understand the HW material? (1=extremely } \\
\text { easy; } 5=\text { extremely difficult) }\end{array}$ & $\begin{array}{l}2.91 \\
(1.0)\end{array}$ & $\begin{array}{l}3.83 \\
(.74)\end{array}$ & 0.000 & 4.838 & 1.10 \\
\hline $\begin{array}{l}\text { Rate your agreement: "I would have } \\
\text { preferred a different HW method for } \\
\text { learning the HW \#4 assignment" } \\
\text { (1=somewhat disagree*; } 5=\text { strongly agree) }\end{array}$ & $\begin{array}{c}1.63 \\
(1.02)\end{array}$ & $\begin{array}{c}3.90 \\
(1.24)\end{array}$ & 0.000 & 9.138 & 2.07 \\
\hline Values are means (std. deviations). & ronol & $\begin{array}{l}\text { el unin } \\
\text { gree.” }\end{array}$ & & & een \\
\hline
\end{tabular}


understand, and they preferred it more over alternative approaches than paper HW users did. Similar results showing strong preferences for Circuit Tutor were obtained on the AC Analysis homework assignment.

When asked to provide comments on the homework methods, those who used Circuit Tutor in Fall 2019 stated that receiving immediate feedback was helpful. Some examples included:

I appreciate Circuit Tutor because it is great for practicing problems and you know your mistakes. With paper problems you could be doing it wrong and not know until you get feedback from someone which sometimes can be too late to help.

Circuit Tutor is a perfect replacement for paper homework because students are still able to work with and transform circuits without having to rewrite the circuit every time. This saves on the time students lose by drawing circuits rather than learning more about them.

However, there were some comments that transitioning from CT to handwritten problem solving on quizzes was tedious when not practicing that technique for homework. As one person stated,

I really like Circuit Tutor, but if that is the only experience you have of circuit simplification and analysis then doing a quiz/test on paper is a rude awakening.

Those students who were assigned to complete the textbook problems reiterated the above statement by indicating that, "Being a written assignment, it felt closer to exam conditions than Circuit Tutor" and "It replicates what an exam would be like."

\section{Student Usage and Overall Evaluations}

To date, this system has been used by over 6000 students and 59 distinct instructors in 159 class sections at 13 different colleges and universities. A comprehensive end-of-semester survey was employed to assess the most recent expanded version of the software in Fall 2019 at three participating institutions. Results of this survey are summarized in Fig. 5. The item "Circuit Tutor exhibits ease of use" is actually an average of three separate related items: "The supporting instructions for using Circuit Tutor were clear and easy to follow," "I quickly and easily learned how to use Circuit Tutor," and "Circuit Tutor was easy to use." The percentages of students who found Circuit Tutor helpful to learn the material were quite high, though in this and in other categories the responses were more positive from students at ASU where the software was developed than at the two heavily minority-serving institutions, Morgan State University (MSU) and The University of Texas at El Paso (UTEP). Some of this difference may be due to the different typical student backgrounds and populations at each institution. Students at MSU and UTEP tended to find the exercises at the higher levels of difficulty more challenging than did many of the students at ASU, though some students there were also challenged by them. It may be desirable to introduce more features to customize the level of the exercises to different student populations and to give instructors more flexibility on which levels they can choose to assign. Such adaptations will be explored in future work.

The biggest differences between institutions appeared to be on the preference between Circuit Tutor and other options, which may reflect the use of different electronic homework systems at different institutions. For example, WileyPLUS is used at ASU and Pearson's 


\section{Percentage of Responses Who Agree or Strongly Agree}

Circuit Tutor was useful in helping me understand the class content.

I prefer Circuit Tutor exercises to others (e.g., textbook or WileyPLUS).

I would like to use Circuit Tutor again.

Circuit Tutor exhibits ease of use.*

I like the look and layout of Circuit Tutor.
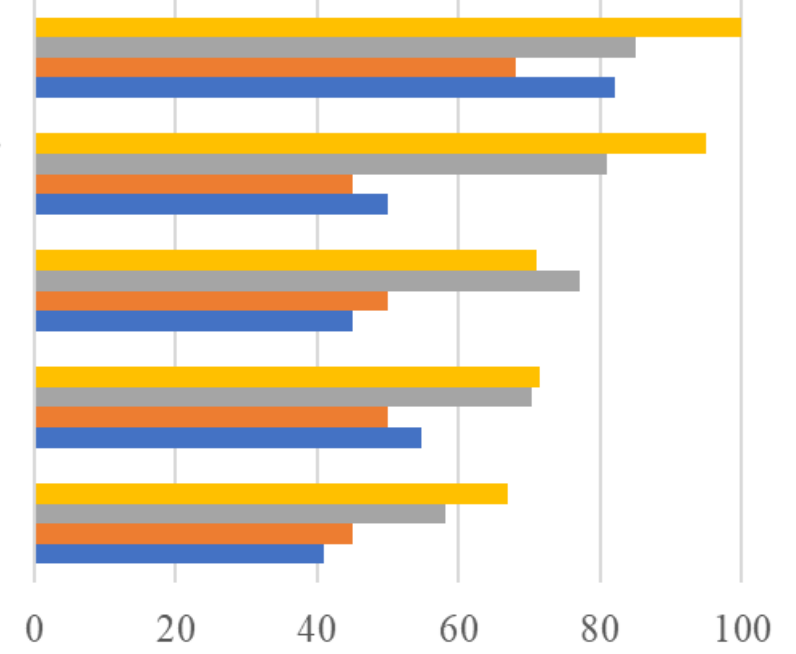

\section{$\square$ ASU Sect. $1 \square$ ASU Sect. $2 \square$ MSU $\square$ UTEP}

Fig. 5. Results of an end-of-semester survey at three different institutions in Fall 2019 covering the entire Circuit Tutor system (not just the topics covered in the randomized experiments).

MasteringEngineering is used at UTEP. A sizable fraction ( 73\%) of students at ASU would like to use Circuit Tutor again, but percentages at the other schools were at or a bit below 50\%. The lowest ratings were on the somewhat dated look and feel of the program, due to the limitations of the platform used to develop it. We will explore options to improve the graphical appearance within the constraints of the platform. The significant number of new help videos being made available in Spring 2020 should help to improve the ease of use, and other options to do so will be explored. In particular, better links to instructional information on the program are being incorporated into the web site and the downloadable software.

\section{Conclusions}

A step-based tutorial system focused on linear circuit analysis has been expanded to incorporate immediate feedback on on-screen editing operations on circuit diagrams, which to our knowledge has not previously been implemented. Advanced simplification methods have also been incorporated in the program. These capabilities have enabled development and use of new tutorials covering topics such as superposition, source transformations, and Thévenin/Norton equivalent circuits in both DC and AC domains (to be extended later to the Laplace domain). A full range of introductory interactive tutorials similar to a textbook has now been introduced that covers nearly all currently supported topics. Video help is now available for virtually every level of every exercise in the program to demonstrate both use of the program interfaces and the technical content. Transcripts of student work are being introduced to support later studying and review, to overcome a traditional limitation of electronic tutoring systems.

Assessment activities have included randomized, blind experiments in three different large class sections to assess both student learning and preferences in the newly developed tutorials that 
require extensive use of the circuit editor. No significant difference in learning outcomes was found in Spring 2019 on these topics compared to the commercial WileyPLUS system, but students preferred the step-based system by wide margins (68-84\%), in keeping with prior results on other modules. In Fall 2019, a randomized comparison to the use of paper homework yielded a statistically significant improvement in learning outcomes on post-tests with effect sizes of $0.54-0.64 \sigma$ in one class section with lower average performance, but a section with higher average performance showed no statistically significant difference. Both sections however showed very strong preferences for the step-based system over traditional paper homework, due to the detailed guidance, graded levels of difficulty, and immediate feedback provided by the former. Overall assessments of the system showed generally positive student feedback, though it was more positive at the large public university in comparison to the minority-serving institutions.

Some students did express a preference for working problems on paper, because doing so is more similar to working problems on exams (without the guidance and scaffolding that Circuit Tutor provides), and because doing so gives them more freedom and physically writing out solutions help aid memory. These comments are very well taken, and we believe that the optimal approach likely involves using the step-based system for the majority of the HW, followed by a problem or two that must be worked on paper to transition to a more exam-like scenario. The tutoring system could be adapted to generate the problems automatically for these paper exercises and check the final answers (without the detailed guidance and step-based input normally used), and thereby still offer the advantage of rapid feedback while preventing the use of solution manuals and copying. This approach will be explored in future work.

\section{Acknowledgments}

This work was supported by the National Science Foundation through the Improving Undergraduate STEM Education and Transforming Undergraduate Education in Science, Technology, Engineering and Mathematics Programs under Grant Nos. 1821628, 1044497, and 1323773. We thank J. Aberle, G. Abousleman, M. Ardakani, J. Blain Christen, S. Chickamenahalli, S. Dahal, A. Ewaisha, R. Ferzli, G. Formicone, S. Goodnick, R. Gorur, O. Hartin, S. Jayasuriya, G. Karady, R. Kiehl, H. Mao, B. Matar, A. Maurer, D. Meldrum, B. Moraffah, C.-Z. Ning, S. Ozev, L. Sankar, A. Shafique, W. Shi, D. Shin, M. Tao, C. Tepedelenlioglu, T. Thornton, G. Trichopoulos, D. Vasileska, C. Wang, Y. Weng, M. Wong, Yu Yao, Hongbin Yu, and Hongyu Yu for using our software in their sections of EEE 202 at ASU. We thank W. Thompson II and Y. Astatke for using our software at Morgan State University, H. Underwood, R. Fish, and D. Pratt for using it at Messiah College, J. D. Irwin for using it at Auburn University, J. Ross and H. Xu for using it at University of the Pacific, V. Gupta for using it at the University of Notre Dame, A. Holmes for using it at the University of Virginia, G. Gilmore for using it at North Carolina A\&T State University, O. Nare for using it at Hampton University, and T. Frank and B. Matar for using it at Glendale, South Mountain, and ChandlerGilbert Community Colleges. We thank Don Fowley of John Wiley \& Sons, Inc. for supporting the project. 


\section{References}

[1] K. VanLehn, "The relative effectiveness of human tutoring, intelligent tutoring systems, and other tutoring systems," Educat. Psychologist, vol. 46, pp. 197-221, 2011.

[2] C. D. Whitlatch, Q. Wang, and B. J. Skromme, "Automated problem and solution generation software for computer-aided instruction in elementary linear circuit analysis," in Proceedings of the 2012 American Society for Engineering Education Annual Conference \& Exposition.

Washington, D.C.: Amer. Soc. Engrg. Educat., 2012, pp. Paper 4437.

[3] B. J. Skromme, C. D. Whitlatch, Q. Wang, P. M. Rayes, A. Barrus, J. M. Quick, R. K. Atkinson, and T. Frank, "Teaching linear circuit analysis techniques with computers," in Proceedings of the 2013 American Society for Engineering Education Annual Conference \& Exposition.

Washington, D.C.: Amer. Soc. Engrg. Educat., 2013, pp. 7940-1-7940-11.

[4] B. J. Skromme, P. J. Rayes, C. D. Whitlatch, Q. Wang, A. Barrus, J. M. Quick, R. K. Atkinson, and T. S. Frank, "Computer-aided instruction for introductory linear circuit analysis," in Proceedings of the 2013 IEEE Frontiers in Education Conference. Piscataway, NJ: Inst. Electrical \& Electronics Engrs., 2013, pp. 314-319.

[5] B. J. Skromme, P. J. Rayes, B. Cheng, B. McNamara, A. S. Gibson, A. Barrus, J. M. Quick, R. K. Atkinson, Y.-F. Huang, and D. H. Robinson, "Expansion and evaluation of a step-based tutorial program for linear circuit analysis," in Proceedings of the 2014 American Society for Engineering Education Annual Conference \& Exposition. Washington, D.C.: Amer. Soc. Engrg. Educat., 2014, pp. 10301-1-10301-14.

[6] B. J. Skromme, P. Rayes, B. E. McNamara, X. Wang, Y.-F. Huang, D. H. Robinson, X. Gao, and T. Thompson, "Recent progress in step-based tutoring for linear circuit analysis courses," in Proceedings of the 2015 American Society for Engineering Education Annual Conference \& Exposition, Seattle, WA, 2015, pp. 14118-1-14118-16.

[7] B. J. Skromme, P. J. Rayes, B. E. McNamara, V. Seetharam, X. Gao, T. Thompson, X. Wang, B. Cheng, Y.-F. Huang, and D. H. Robinson, "Step-based tutoring system for introductory linear circuit analysis,” in Proceedings of the 2015 IEEE Frontiers in Education Conference, 2015, pp. 1752-60.

[8] B. J. Skromme, B. E. McNamara, X. Gao, B. Korrapati, V. Seetharam, Y.-F. Huang, and D. H. Robinson., "Interactive tutorial system for linear circuit analysis: Impact on learning and novel tutorials," in Proceedings of the 2016 American Society for Engineering Education Annual Conference \& Exposition, New Orleans, 2016, pp. 25439-1-25439-16.

[9] B. J. Skromme, V. Seetharam, X. Gao, B. Korrapati, B. E. McNamara, Y.-F. Huang, and D. H. Robinson, "Impact of step-based tutoring on student learning in linear circuit courses," in Proceedings of the 2016 IEEE Frontiers in Education Conference. Piscataway, NJ: Inst. Electrical \& Electronics Engrs., 2016, pp. 1-9.

[10] B. J. Skromme, S. K. Bansal, W. M. Barnard, and M. A. O’Donnell, “Step-based tutoring software for complex procedures in circuit analysis," in Proceedings of the 2019 IEEE Frontiers in Education Conference. Piscataway, NJ: Inst. Electrical \& Electronics Engrs., 2019.

[11] J. Hamari, J. Koivisto, and H. Sarsa, "Does Gamification Work? - A Literature Review of Empirical Studies on Gamification,” in 47th Hawaii International Conference on System Science, 2014, pp. 3025-3034.

[12] B. J. Skromme and D. H. Robinson, “Addressing barriers to learning in linear circuit analysis,” in Proceedings of the 2015 American Society for Engineering Education Annual Conference \& Exposition, Seattle, WA, 2015, pp. 14125-1-14125-15.

[13] A. Edgcomb, F. Vahid, R. Lysecky, and S. Lysecky, "Getting Students to Earnestly Do Reading, Studying, and Homework in an Introductory Programming Class," in Proceedings of the 2017 ACM SIGCSE Technical Symposium on Computer Science Education. Seattle, Washington, USA: Association for Computing Machinery, 2017, pp. 171-176. 
[14] M. Liberatore, "High textbook reading rates when using an interactive textbook for a material and energy balances course,” Chem. Engr. Education, vol. 51, pp. 109-118, 2017.

[15] Y. Hu and H. Lyu, "Researching an effective interactive e-book for programming courses," in Advances in Graphic Communication, Printing and Packaging, vol. 543, Lecture Notes in Electrical Engineering, P. Zhao, Y. Ouyang, M. Xu, L. Yang, and Y. Ren, Eds. Singapore: Springer, 2019, pp. 416-420.

[16] B. J. Skromme, https://www.youtube.com/channel/UCnn_0DTFVFpiorlWiTTUVvg/videos.

[17] J. D. Irwin and R. M. Nelms, Basic Engineering Circuit Analysis, 11th ed. Hoboken, NJ: Wiley, 2013. 